\title{
SEBASTIÁN VIZCAÍNO Y FRAY ANTONIO DE LA ASCENCIÓN, UNA NUEVA ETAPA EN EL RECONOCIMIENTO DE LAS CALIFORNIAS NOVOHISPANAS: ESTUDIO SOCIO-HISTÓRICO*
}

\author{
Por \\ María Luisa Rodríguez-Sala**
}

\begin{abstract}
RESUMEN
Durante la segunda mitad del siglo XVI y el XVII, los viajes auspiciados por la corona española le brindaron el dominio sobre la ruta a oriente. En este documento se realiza un esfuerzo por rescatar la información biográfica del navegante y explorador español Sebastián Vizcaíno, quien realizara dos travesías hacia la Alta y la Baja Califormias. Para tal fin se acudió a fuentes primarias como el Archivo General de la Indias ( $A O 1$ ) y el Archivo General de la Nación (AGN), así como a diversas fuentes secundarias. Además, haciendo uso de un enfoque interdisciplinario socio-histórico, se reseñan los pormenores de las travesías realizadas por Vizcaíno, en especial se hace énfasis en los descubrimientos geográficos y expansión de conocimiento científico derivados del segundo viaje realizado por Vizcaíno y fray Antonio de la Ascención hacia estas tierras californianas.
\end{abstract}

\begin{abstract}
During the second half of the sixteenth century and into the seventeeth, the voyages backed by the Spanish crown geve the Spanish control of the route to the East. This document mekes an effort to rescue the biographical information of the seafarer and explorer Sebastián Vizcaíno, who made two crossings to Upper and Lower California. The information was gathered from primary sources such as the Archivo General de las Indias (AGI) and the Archivo General de la Nación (AGN), as well as from a number of secondary sources. In addition, using an interdisciplinary socio-historical focus, the details of Vizcaino's voyages have been described, with particular emphasis on the geographical discoveries and the increased scientific knowledge derived from the second trip which Vizcaino and Fray Antonio de la Ascenciónmade to the California.
\end{abstract}

* Colaboración de María Eugenia Cué e Ignacio Gómezgil, R.S.

** Investigadora del Instituto de Investigaciones Sociales de la Universidad Nacional Autónoma de México. 


\section{LOS ANTECEDENTES}

Los viajes por las costas occidentales más allá de las fronteras septentrionales de la Nueva España, además de sus objetivos específicos, conllevaban los generales de localizar el paso entre los dos océanos y explorar las posibilidades de continuar la travesía hacia el poniente.

Fue así como la corona española, a través del virreinato de la Nueva España, apoyó y auspició durante la segunda mitad del siglo XVI las exploraciones en la ruta poniente. El éxito se alcanzó plenamente a partir de los viajes a las Filipinas, durante 1565, de Miguel López de Legazpi y del afortunado retorno de fray Andrés de Urdaneta. Desde ese momento España quedó como la dueña absoluta del camino al Oriente al establecer la ruta marítima y comercial entre Espanta y Filipinas pasando por la Nueva España. Sin embargo, sus enemigos europeos estaban al acecho y pronto los ataques de los corsarios ingleses se dejaron sentir duramente y obligaron a la corona española a tomar nuevas medidas políticas. Éstas se plasmaron en actividades de protección que comprendían cuatro puntos: poblar parte de la costa de California, encontrar y asentarse en las entonces no consideradas míticas, sino reales, islas Rica de Oro y Rica de Plata, explorar las costas de China y Japón y encontrar el legendario estrecho que comunicaría los dos océanos, desde entonces llamado de Anián (Del Portillo, 1982).

Con base en esta política se entienden las expediciones que figuraron entre la época de los ataques piratas de Drake y Cavendish y el primer viaje de Sebastián Vizcaíno. En ese periodo fueron dos las expediciones de referencia. La primera, la que auspició el virrey-arzobispo, Pedro Moya de Contreras y realizó el cartógrafo y navegante Francisco Gali en 1583. Este personaje llegó a Macao, en su viaje de regreso a México, alcanzó los 37 grados de latitud norte sobre costas de California, volví a Macao y murió en esa ciudad. La segunda contó con el apoyo del siguiente virrey, marqués de Villamanrique, quien encomendó a Pedro de Unamuno la flota que partió de regreso desde Macao. Su cometido principal fue localizar y poblar las dos islas legendarias, después de largo tiempo de navegación, como era de esperarse, la búsqueda resultó inútil y la flota emprendió el regreso por la misma ruta de Gali, bajó por costas califomianas desde los 37 grados latitud norte hasta la bahía de Santa Cruz o del Morro, en la que se tomó posesión y se regresó directamente al puerto de Acapulco. Sucedía esto durante el afio de 1587.

Casi al mismo tiempo la "Nao de la China" sufrí́ uno más de los ataques corsarios, el de Thomas Cavendish frente al extremo sur de la península bajacalifomiana. No sólo fue el galeón el atacado, ya meses 
antes, el pirata inglés en su trayecto desde el estrecho de Magallanes habia remetido contra los.puertos desprotegidos del litoral espanol en el Pacifico sur y en las costas centroamericanas. Estos acontecimientos se produjeron en uno de los momentos más críticos del gobierno de Felipe II, la derrota de la Armada Invencible a manos de los ingleses. Una de las muchas consecuencias de esta derrota espafiola se manifestó en un cambio en la estrategia política de la corona en relación con las expediciones. Entre las órdenes reales restrictivas figuró la de suspender los viajes de demancación de las costas externas de las Californias, limitándose exclusivamente a la incursión en las del Mar de California con fines mayoritariamente de explotación perlífera. He aquí la aparición de una nueva etapa cuyo sustrato fue esencialmente político y económico, motivos que repercutirian también en una contracción de la, hasta entonces, brillante y creciente actividad científica de la sociedad espafiola. Se pasaba, asi, de un objetivo exploratorio-científico a uno económico-comencial, que, afortunadamente, tendría en las últimas décadas del siglo XVI una corta duración.

Antes del declinar de la importancia española en los descubrimientos geográficos y la expansión del conocimiento cientifico producto de éstos, la corona espantola tuvo aún destellos de reacción positiva. Los que se manifiestan en la gran empresa de Sebastián Vizcaino, particularmente en el segundo de sus viajes.

\section{ASPECTOS FAMILIARES Y PROFESIONALES DE SEBASTIÁN VIZCAÍNO}

Como ya es usual para los navegantes y exploradores del siglo XVI y parte del XVII,los datos biográficos de Sebastián Vizcaino son escasos y resulta difícil ampliar lo que ya otros estudiosos han logrado; sin embargo, el regreso a las fuentes primarias, permite a cada investigador un renovado análisis desde particulares ópticas y perspectivas acordes a los objetivos de su trabajo científico. Es asi que, reconocemos y partimos de trabajos anteriores, especialmente los de Álvaro del Portillo y Michael Mathes, pero hemos tratado, cuando ha sido posible, regresar a las fuentes primarias. A partir de una cuidadosa revisión buscamos destacar e incluir aquello que consideramos especialmente valioso para el estudio de las aportaciones científico-técnicas que se desprenden de las actividades del navegante Sebastián Vizcaíno, desde un particular enfoque interdisciplinario, el que confiere lo socio-historico.

En visita especial al Archivo General de las Indias (AGI) consultamos la documentación ahí concentrada y a partir de ella, combinada con la 
procedente del Archivo General de la Nación (AGN) y con la información de fuentes secundarias, hemos ampliado y completado ciertos aspectos biográficos de Vizcaíno. Una de las fuentes más ricas es el legajo: Asiento y capitulación que incluye varios documentos, entre ellos, su Información de parte y oficio de méritos y servicios.

Abre este documento la petición del general Sebastián Vizcaíno de fecha 20 de noviembre de 1602 a la Real Audiencia de recibirle su Información, lo que le permitirfa solicitar al rey una merced de justicia con base en el resultado de la revisión de lo informado. Solicitó, expresamente para sí y sus tres hijos, algún oficio de justicia en esa tierra o en otra, o bien una encomienda de indios en nombre de los servicios prestados, tanto de guerra como en la navegación del Mar del Sur. Para ello anexó los temas o preguntas que se formularían a los testigos encargados de establecer la exactitud de lo asentado por el general Vizcaino en su Información de servicios. Si bien el documento carece de algunos folios, se pueden reconstruir, con cierta aproximación, los hechos familiares y profesionales más relevantes de la vida de Sebastián Vizcaino hasta el año de 1602.

Según Del Portillo el navegante nació en 1548 probablemente en Extremadura, otros autores como Gaspar de Villagrán y Wagner lo consideran cántabro o de las Vascongadas. Algunas fuentes primarias adicionales, petmitirian seffalar que el año de nacimiento fue posterior, entre 1555 y 1560 , ya que los testigos presentados para otorgarle la aprobacion de embarque para su segunda salida de Espafla, declararon en 1607, que su edad era de más de 47 affos. En cuanto a sus antecedentes familiares, sabemos de su propio testimonio, rendido en la Información, que pertenecio a una familia destacada. La inicial y única referencia en este sentido asienta que aun en España sirvió muy joven, en el año de 1577, al rey durante la campanta de pacificación de Portugal, al acudir con sus armas y caballos. Dependra aún de su familia, ya que fue su padre quien gastó gran cantidad de pesos de oro en este acto militar, su progenitor era caballero de cuantía e hijodalgo de notoria calidad.

Probablemente hayan sido sus padres Sebastián Vizcaíno y Ana Ruiz, vecinos de Almodóvar del Campo, de quienes se dan las referencias en relación con la información rendida para la licencia de salida de Ana Ruiz, pasajera a la Nueva Espanfa y, también probablemente, hermana de Sebastián. En difícil asiento de Contratación localizamos la licencia de pasajeros de esta Ana Ruiz casada con Francisco Martínez, de oficio boticario, ambos naturales de la población arriba citada. A la fecha de la

\footnotetext{
1 AGI. PATRONATO, 30, R, Documento 3: Asiento y capitulación.
} 
salida de España, 1595, Ana Ruiz tenía 40 años de edad, fue hija legítima de Sebastián Vizcaíno y su mujer Ana Ruiz, para entonces ya difuntos. Con base en estos datos, $y$ en forma no definitiva, podríamos asentar su parentesco con el explorador Vizcaíno y de ahí deducir que el navegante pudiera haber nacido en esa misma población que pertenecía a la provincia de Ciudad Real del arzobispado de Toledo en Castilla la Nueva. El matrimonio de Ana y el boticario viajó en 1595 a la Nueva España, en compantía de sus hijas Mariana, Antonia y María. ${ }^{2}$

Don Sebastián Vizcaíno pasó en 1583 a la Nueva España, sus estudiosos así lo consignan, pero no localizamos asiento de pasajero en ninguna de las fuentes del Archivo de Indias. Su propio testimonio afirma que en 1586 se embarco en Acapulco para las Filipinas en donde permaneció hasta 1589 sirviendo en todo lo que se ofrecía, inclusive participó en los trabajos para la edificación del fuerte de la ciudad de Manila y aportó, además, cien pesos de oro para su construcción. Regresó a la Nueva España en 1589 y se avecindó en la capital en donde se convirtió en próspero negociante y comerciante lo que le permitiría la realización de sus empresas exploratorias por el Mar del Sur y probablemente el recibir a su hermana y cufiado.

Es probable que para ese tiempo hubiera contraído matrimonio con Magdalena Martínez Orejón con quien tuvo sus tres hijos, Juan, Lorenzo y Ana. Esta última se casó con el contador Martín de Lezama y de esa unión, que esté documentado, nació un hijo, Nicolás, quien años más tarde, reclamaría los derechos de población, pacificación y consecuente evangelización de las Californias, basándose en los servicios y méritos de su abuelo, así como en los apoyos que para continuar estos viajes había realizado su padre en el aflo de 1628 . El entonces contador del tribunal de cuentas de la Real Audiencia, don Martín de Lezama ${ }^{3}$ solicitó permiso para ausentarse del cargo por seis meses con el fin de vigilar la preparación del navio que por su cuenta fletó para continuar la exploración de las Californias, fue sin duda el viaje en el que participó como carpintero de ribera el que más tarde sería capitán, explorador y explotador de las riquezas perlíferas califomianas, Francisco de Ortega.

\footnotetext{
2 AGI. CONTRATACION, 5250 N.2, R.32.

3 Por un error se ha consignado en trabajos anteriores de otros historiadores y de nosotros mismos, sobre Francisco de Ortega, el nombre de Melchor en lugar de Martin, como el yemo de Sebastián Vizcaíno, en la consults de fuentes primarias realizada en AOG en abril de 1995. nos hemos percatado de este error y lo corregimos ahora.

AGI. GUADALAJARA, 134, "Documentos relativos al capitán Bemardo Ruiz de Pinadero, cabo y almirante del reino de California". fol.368v.
} 
En cuanto a los dos varones, sólo hemos localizado el registro bautismal del primero de ellos, se asienta que, con fecha 3 de mayo de 1590 , fue bautizado en la Santa Iglesia Catedral por el licenciado Bautista de Mendieta, fue su padrino Gonzalo Sánchez de Sermeras. ${ }^{5}$ Fue este hijo el compañero de viajes de Sebastián, primero en las jomadas de California y más tarde, en el que realizaron a España, probablemente hacia 1606. Regresaron padre e hijo a la Nueva España, en noviembre de 1607 y fueron registrados como pasajeros en la Casa de Contratación junto con: un criado, Francisco Rodríguez, su personero y también criado, Bartolomé Sánchez Dorado y dos esclavos negros, Francisco y Sebastián, todos ellos habian venido de la Nueva España y regresaban a ella con licencia real. La información adjunta incluida en los trámites de salida, establece que don Sebastián tenía, en ese afio, más de 47 años de edad, era de buen cuerpo, colorado y con una señal de herida en el lado izquierdo de la cabeza y el joven Juan ${ }_{6}$ también de buen cuerpo y barbado, de más o menos diez y ocho afios. ${ }^{6}$ Se tiene documentado el regreso, pero en su lícencia no se consigna cuál fue el motivo de ese traslado, muy posiblemente los Vizcaíno trataron de conseguir en la corte metropolitana una mayor retribución a sus servicios en las Jornadas de Califormia y probablemente autorización para continuar las exploraciones en aquellas costas.

Pero, no todo estaba absolutamente sujeto a la decisión real, ya en la Nueva España el navegante don Sebastián habla recibido un primer reconocimiento. Después de su regreso de la segunda jornada a las Californias el virrey conde de Monterrey le dio, en 1603, nombramiento de general de las naos que saldrían de Acapulco para ir a las Filipinas y de regreso demarcar las islas y costas; sin embargo, no se llegó a consolidar esa nueva jornada por muerte del virrey. Su sucesor, el marqués de Montesclaros, dejo pendiente el viaje al Oriente y otorgó a Vizcaino el cargo de alcalde mayor de Tehuantepec y su provincia, encomendándole su gobernación, con sólo su salario de alcalde. Más tarde y como consecuencia de su viaje a España, en la flota que partió de la Veracruz en el año de 1604 , en donde informó detalladamente al Consejo de Cámara en Madrid de sus servicios prestados, el rey le otorg 6 la merced de dos mil ducados de renta por tres vidas en los almojarisfagos del puerto de Acapulco. Además le confirmó y otorgó en propiedad el nombramiento de general de la carrera de las dichas Islas que le hiciera el virrey con salario

5 La colaboradora, Rosalba Tena Villeda, estudiante de historia en la Facultad de Filosofia y Letras, UNAM, localizó el documento en AGN; Ramo de Heráldica y Genealogla, Sagrario Metropolitano, Bautizo de Españoles, Libro 5, Fs.7.

6 AGI., CONTRATACIÓN, 5298, N.2, R.11 y 12 y 5539, L.1, F. 126. 
y raciones con cargo a la caja real de la ciudad de México. En reconocimiento a los descubrimientos que hiciera en el Mar del Sur, se le concedieron las gracias y franquicias de todo descubridor y fue por ello que el rey ordenó se le adjudicara una encomienda de indios vacante o que vacare $y$, en tanto, se le diera una renta de mil pesos en cada affo. ${ }^{7} \mathrm{La}$ encomienda recibida fue en el pueblo de Sayula provincia de Ávalos, en el actual estado de Guanajuato. Como era lo usual, fue el propio Vizcaino quien solicitó y, casi exigió, el otorgamiento de esas mercedes reales. precisamente en su traslado a Espafia. Son estos beneficios los que más tarde, su nieto, Nicolás Vizcaíno de Lezama reclamo, junto con los títulos de su abuelo, en especial frente a las exploraciones, poco escrupulosas del que se hizo llamar almirante de las Californias, Bemardo Ruiz de Pinadero, con permiso del virrey conde de Bafios. El nieto de Vizcaino buscó y obtuvo el apoyo oficial para continuar la población y pacificación de las Californias, además de ser nombrado gobernador de Sinaloa, llave y puerta de esta otra monarqula, sucedio esto en el afio de $1675 .{ }^{8}$ Otro de los nietos, por parte de su hijo Juan, también protestó ante los viajes de Pinadero, se trataba del capitán don Juan Vizcaíno Urrutia de Contreras, vecino del pueblo de Sayula en la provincia de Ávalos, con seguridad en la encomienda que recibiera su abuelo y heredara a su hijo mayor."

Uno de los rasgos de la actividad de Vizcaíno radica en que permanentemente propugnó por hacer un hecho la población de parte de las costas que descubriera en su segundo viaje a las Californias, aquel en el que demarcó y señaló la importancia del puerto de Monterrey. Al respecto escribió una carta interesante al rey el 3 de diciembre de 1607 en la cual defiende la posibilidad de poblamiento de dicho puerto frente a la política contraria ejercida por el virrey Marqués de Montesclaros ${ }^{10}$ con quien Vizcaíno no llevó buenas relaciones. Los argumentos que manejó el general en favor del poblamiento del puerto, estuvieron en estrecha relación con los peligros a los que se vefan expuestas las naos de la carrera de las Filipinas. Especialmente preocupó a Vizcafno, por propia experiencia, las situaciones adversas del viaje cuando las naos se enfrentaban a las frecuentes tormentas. Considero el general las circunstancias a las que se tenían que enfrentar al no contar con un posible puerto de abrigo cercano, lo expresó con las siguientes palabras:

\footnotetext{
AGI., INDIFERENTE, 449, L.A1, fols 113-114.

AGI., GUADALAJARA, 134 , fols.368v y 381.

AGI., GUADALAJARA, 134,fol.382.

AGI., MÉXICO, 27, N.18, documento 5.
} 
...la necesidad las obliga a volver atrás y a desandar lo andado y ponerse en riesgo de perderse en el Japón y islas de los ladrones como ha sucedido muchas veces y si el dicho puerto de monterrey estuviera poblado de españoles cosa es de años que sí vinieran a él pues es la mitad del viaje de mar, que cuando llegan a él vienen con la necesidad forzosa de bastimentos y salud, por cuya causa muere mucha gente todos los años. ${ }^{11}$

La consecuencia de la larga travesía, aproximadamente de tres meses, desde las Filipinas hasta el puerto de Acapulco eran bien conocidas de todo aquel que hubiera tenido esa experiencia marítima; cuando se corría con suerte se arrivaba al puerto en pésimo estado de salud, con mucha frecuencia la muerte sobrevenía durante las últimas semanas, como se verá más adelante, a causa del escorbuto, la fatal enfermedad que aparecía, sin remedio en aquellos siglos, durante los viajes marítimos prolongados. Vizcaíno le comenta al rey esta situación:

Desde el puerto de Monterrey hasta el de Acapulco cuya verdad es tan sabida que desde que las Filipinas se descubrieron hasta hoy han muerto en este paraje más de dos mil vasallos de Vuestra Magestad, de gente de guerra, marineros, pasajeros, y este daño cesará con que el dicho Puerto de Monterrey se pueble, como tengo advertido... ${ }^{12}$

Sabemos que después de su regreso del viaje al Japón, volvió a sus actividades de encomendero y comerciante en ropa suntuaria, la que trajo de su viaje al Japón. Para el año de 1614 estaba encamado y tullido y vivía en la capital novohispana, ${ }^{13}$ don Sebastián murió en la ciudad de México en 1628 (Del Portillo, 1982:238), en avanzada edad para la época, aproximadamente, entre 65 y 70 años.

No se conocen más detalles de su vida familiar, pero sí que llevó una larga vida de servicios oficiales como militar, navegante-descubridor y embajador y que, por su cuenta trató siempre de realizar comercio con la riqueza periffera de las Californias, sin que realmente lo hubiese logrado. Sobre estas actividades hablaremos en el siguiente apartado.

\section{ACTIVIDADES DE SEBASTIÁN VIZCAÍNO ADICIONALES A SUS VIAJES A LAS CALIFORNIAS}

La larga vida de Vizcaíno no se limitó a su participación en la exploración y descubrimiento de partes de la Baja y la Alta Californias; su temprana

11 AGI., MÉXICO, 27, N.18, documento 4.

12 AGI., MÉXICO, 27, N.18, documento 4.

13 AGI., FILIPINAS 1, R.4.fol.220. 
presencia en Filipinas y en la Nueva España, su experiencia marítima, su agudo sentido práctico, militar y comercial, pero, fundamentalmente su capacidad de adaptación a las cambiantes reglas del juego político y de los intereses de la corona, le permitieron desplazarse y participar en actividades varias. La descripción de ellas y su análisis permiten una más amplia perspectiva de este personaje que transcurre encabalgado entre dos etapas de la expansión española en el Mar del Sur, la exploratoria-descriptiva y la exploratoria-comercial. Previo al análisis de su participación en los dos viajes, comentaremos brevemente en este apartado sus restantes actividades profesionales al servicio de la corona española en el Nuevo Mundo.

\section{Empresas defensivas}

A los pocos años de su regreso de Manila y cuando preparaba ya la primera jornada hacia las Califomias, durante 1597 se avistaron en las Islas de Mazatlán tres navíos de corsarios ingleses que se dirigian a Cabo San Lucas con la intención de atacar a las naves que venían de las Filipinas. El virrey, conde de Monterrey, ordenó a Vizcaíno que con gente de mar y guerra saliera a reconocer $y_{i}$ en su caso, diera aviso a los barcos españoles del probable ataque corsario. Navegó toda la costa desde Acapulco hasta el extremo suroeste de la California sin avistar las naos piratas y, a pesar de haber sido una comisión oficial, no recibió por ello pago alguno, según lo escribe en su Información de servicios que rindió ante la Real Audiencia, ${ }^{14}$

Probablemente una de las últimas hazañas de Vizcaíno fue su participación en el ataque al pirata holandés Spielbergen, cuando intentó desembarcar en el puerto de Zacatula o Salagua en la desembocadura del río Balsas en los primeros días del mes de noviembre de 1615. Pocos días antes la flota de Nicolás de Cardona, que regresaba de la península con cargamento de perlas y metales preciosos, había sido atacada por los piratas holandeses. Vizcaíno fue comisionado para la defensa de los puertos de esta parte de la costa occidental, pertenecientes a la jurisdicción de Colima. Se le dowó de gente de guerra, aproximadamente 200 soldados y de armas y municiones para la defensa. Como general que era tuvo una afortunada defensa estratégicamente planeada que le permitió obligar al holandés, sus bajeles y su gente a emprender la huida, y tomándole algunos prisioneros, quienes informaron del proyectado ataque a las ciudades de

${ }^{14}$ AGI., PATRONATO 30, R.1, Documento 2. Asiento y capitulación. 
las Filipinas. ${ }^{15}$ Fue esta la última acción armada de Vizcaíno de la que se tiene noticia.

\section{La embajada en el Japón}

Después de haber concluido sus dos jornadas a las Californias, de haber retornado de España y de encontrarse disfrutando de las mercedes reales a él concedidas, recibió su siguiente comisión oficial.

Fue nombrado general de los navíos que deberían partir en 1611 a las Filipinas y embajador español en la misión ante el emperador del Japón. El papel que correspondió a Vizcaíno en este viaje fue también de importancia, ya que se buscaba establecer relaciones comerciales y evangelizadoras con ese país del lejano oriente español, del menos alejado occidente novohispano. Al mismo tiempo se iniciaba el traslado del interés por el poblamiento de las costas califomianas por el del establecimiento de colonias en las legendarias islas que deberian localizarse en el camino entre la Nueva España y el Japón. Fue así como correspondio a este personaje ser el protagonista de parte de la nueva política expansiva española.

Recibió, a expresa solicitud del rey asentada en su cédula relacionada con materias de guerra de Filipinas expedida en San Lorenzo el 19 de agosto de 1606 y enviada al virrey, marqués de Montesclaros, el encargo de ser, precisamente él, por sus conocimientos y experiencia en la navegación de las costas califomianas, quien se dispusiera para ir a las Islas Philipinas, llevando a su piloto mayor o al dicho Almirante, para lo cual ordenó el rey se le socorriese de la real caja con hasta veinte mil pesos. Uno de los objetivos adicionales de este viaje, además de reconocer las islas y costas, fue procurar la población del recién descubiento puerto de Monterrey, en la Alta California, para que en él encontraran abrigo las naves que retornaban de la carrera a las Filipinas. El viaje se retrasó algunos afios y tuvo efecto hasta 1611; el general Vizcaíno escribio desde el puerto de Acapulco el 21 de marzo de dicho año, un día antes de partir, pidiendo a la corona se le reconocieran sus derechos en caso de descubrir las islas Ricas de oro y plata que dicen están en el paraje del Japón. ${ }^{16}$

De regreso en la Nueva España con fecha de 20 de mayo de 1614, el general escribió una carta interesante al rey, en la cual resume los resultados de su embajada en el Japón, vertiendo en ella sus opiniones relativas

${ }_{16}$ AGI., MÉXICO, 28. N.31, fols.1-9.

16 AGI., FILIPINAS 193, R. 1, documento 7, fol.1. 
a ese Reyno. ${ }^{17}$ A través de la lectura de este documento conocemos suscintamente el desarrollo de su viaje, y lo más importante, la situación que deberia corresponder a la corona española en relación con la situación japonesa.

Es asi que sabemos que la travesía de ida tomó poco menos de tres meses, ya que llegó al Japón el 10 de junio. Una vez anclada su nave, pidió permiso al príncipe japonés para presentarse ante los principales, $y$ hacerles entrega de sus despachos que le acreditaban como embajador del monarca espafiol. Fue recibido con grandes cortesías-y autorizado a navegar, demarcar y sondear todos los puertos de la costa oriental japonesa. También está documentado que para agosto de 1612, las naves se encontraban en el puerto de Urangaba de los Reynos de Japón ${ }^{18}$ desde donde se turnó la carta de bienvenida que el príncipe japonés envió al virrey de la Nueva España, a través de la cual, reconocía la amistad y el interés de ese pueblo en establecer relaciones y permitir los viajes anuales de las embarcaciones.

La jornada geográfica fue provechosa ya que descubrió y reconoció muchos de los puertos japoneses hasta la altitud norte de 41 grados. Según su propio escrito, realizó una demarcación graduada, misma que asegura fue anexada en el aviso que el virrey marqués de Guadalcázar envió a la corte durante el mismo año de 1614. Sin embargo, no se encuentra en documentos del AGI. Navegó las costas orientales hasta el mes de septiembre de 1612 en que partio desde el puerto de Urangaba en viaje de regreso a la Nueva Espafia, durante el cual debería, según sus instrucciones, localizar y descubrir las Islas Ricas de oro y Ricas de plata. De acuerdo con información que el virrey marqués de Montesclaros remitió al rey en sus cartas del año de 1607 , concretamente el 27 de mayo, sobre las entonces aún no consideradas míticas sino reales islas, éstas deberian encontrarse de:

...treinta y cuatro a treinta y cinco grados hay dos islas que llaman Rica de Oro y Rica de Plata, oeste al este del Puerto de Monterrey, casi en un mismo paralelo, aunque en gran distancia de longitud estas islas son o cualquiera de ellas las que todos los que han tratado de esta navegación y lo han hecho, dicen que conviene reconocer y poblar para que en ellas hagan las naos escala, conforme a lo cual sería de parecer que el descubrimiento y población de que se trata fuese principalmente de estas islas y que para ello se hiciese instancia por persona de cuidado y fidelidad y entiende que será a propósito la de Sebastián Vizcaíno, porque a más de poder ya sabrá toparse con el

17 AGI., FILIPINAS 1, R.4, fol.220.

18 AGI., FILIPINAS 1, R.4, , fol.211. 
Puerto de Monterrey que tiene conocido y habiendolo de hacer el podra siendo vuestra magestad servido, salir del Puerto de Acapulco por general de las naos del viaje ordinario y desde Manila salir con dos navíos ligeros y desembarcados que no vaya ni a otra cosa mas que al descubrimiento. ${ }^{19}$

Navegó con buen tiempo hasta lo que se le había designado como probable ubicación de dichas islas y las buscó a lo largo de diferentes altitudes, primero, desde los 36 hasta los 38 grados, desde donde inició el retomo y bajo hasta los 34 grados. Ocupó en esta localización hasta el 18 de octubre, por supuesto, sin haberlas hallado. Convencido de su inexistencia decidió continuar el viaje hacia Acapulco, pero fue detenido por una tormenta que les oblig6 a regresar a las costas japonesas y pedir socorro para reparar una de las naves averiadas. Sin embargo, se encontró con muy poca ayuda por parte de aquel príncipe que le había recibido con tanta ceremonia y tuvo que acudir a los religiosos que le facilitaron un navío, propiedad de un japonés principal, que había sido ya empleado en un anterior viaje comercial a la Nueva España. En esa embarcación tưo que acomodar, no solo a toda su gente, también al embajador japonés, representante del rey de Boxu, uno de los más poderosos del Japón. Este príncipe, ya católico, era yemo del emperador y viajó acompanado de un numeroso sćquito de aproximadamente 30 personas; era, además, muy estimado por el religioso franciscano Luis de Sotelo. Estos dos personajes llevaron a cabo una larga embajada, primero ante el virrey novohispano, después ante el rey en Espafla y más adelante ante el papa en Roma. El objetivo fundamental fue el misional, el franciscano tenía la firme intención de lograr amplio apoyo para continuar su trabajo de conversión en tierra japonesa y para ello empleo todas las estrategias posibles. El viaje de regreso de esta comitiva, siempre más largo que el de ida, terminó en el puerto de Acapulco el 28 de enero de $1613 .{ }^{20}$

También conocemos que los religiosos estacionados en el Japón, escribieron al virrey, Marqués de Guadalcázar, que Vizcaíno había arribado con dos naves cargadas de mercancías, prometiendo a los japoneses facilitarles el intercambio comercial, lo que al parecer contravenía las instrucciones que llevaba el general. Esta actitud de los religiosos pudo ser el inicio de una situación encontrada entre la opinión de Vizcaíno y la expresada por el franciscano. ${ }^{21}$

GI, MEXICO, 27, n.18, fol.2v.

20 AGI, MÉXICO, 27, n.18, fol.224.

21 AGI., GUADALAJARA, 134, fol. 380 . 
En AGI no se localizó información más amplia y profunda relativa a esta actividad oficial de Vizcaíno, las Instrucciones recibidas y la Relación que él mismo ofreciera escribir de estos sucesos no pudimos localizarlas, es muy posible que se encuentren en la colección de manuscritos de la Biblioteca Nacional en Madrid. El resultado de este interesante viaje al Japón fue relevante ya que se lograron varios objetivos de diferente índole, científicos, comerciales y políticos, destacamos entre ellos los principales:

A) La demarcación científicamente realizada de las costas orientales japonesas;

B) La comprobación geográfica de la inexistencia de las fabulosas islas Rica de Oro y Rica de Plata de cuya jornada de descubrimiento el propio Vizcaíno escribió que fue una empresa perdida en la cual se gastó dinero inútilmente, ya que...ni las hay en el mundo ni tal se han de hallar eternamente... $^{22}$;

C) La dificultad de establecer relaciones comerciales con Japón, ya que el emperador japonés, si bien deseaba intercambiar productos con España como ya se venía haciendo, no aceptó una de las condiciones esenciales espaniolas, la evangelización y desarrollo de las actividades de los sacerdotes españoles ahí radicados. Más aún se intensificó la persecución católica en el Japón, Vizcaíno hace referencia a la destrucción de las iglesias y el ataque a los sacerdotes y fieles en la ciudad de Endo, de donde fueron desterrados los sacerdotes. En este tema, el general Vizcaíno, en las dos cartas enviadas al rey, expresa, abiertamente su critica a la política de jesuitas y franciscanos, quienes, según él, y en especial, el franciscano Luis de Sotelo, pretendía, al viajar a la corte espaniola y después a Roma, engañar a la corona y al papa al asegurar que sus misiones eran exitosas en el reino de Japón, para poder sustentar su solicitud de apoyo y ayuda económica para ampliar sus actividades misioneras. ${ }^{23}$ Para Vizcaíno era clara la posición de las autoridades japonesas en el sentido de estar totalmente renuentes al establecimiento y ampliación de las actividades de dichos religiosos:

D) La comunicación de Vizcaíno retoma la necesidad de dirigir la atención a la política descubridora y poblacional de la corona hacia las costas de las Californias, en donde, sin mayores gastos ni peligros, era posible ubicar buenos puertos y evangelizar a una población de naturales bien dispuesta, destacando el hecho de que todas las empresas en la Nueva España habían sido provechosas y exitosas.

22 AGI., FILIPINAS 1, R.4, fol.220.

23 AGI., FILIPINAS 1, R.4, fols. 220 y 221. 
E) No sólo las opiniones de Vizcaíno, también las del virrey, Marqués de Salinas y las del acuerdo real, muestran la tendencia a tomar precauciones en cuanto a la aceptación de la embajada japonesa, la cual prácticamente rechazan, aduciendo astucia y engaño por parte del franciscano y del embajador japonés; en tanto que el religioso muestra una diferente cara de la situación. Ante una encontrada y difícil situación: la del general Vizcaíno y las del religioso franciscano y embajador japonés, el rey decidió efectuar consultas adicionales y obtener mayor información procedente de personas con conocimiento de la situación en aquel reino. Para ello pidió la opinión del franciscano fray Alonso Muñoz a quien se hizo venir de Salamanca para entrevistarse con fray Luis de Sotelo y después la de don Francisco de Varte Zerón, oficial del Consejo de Indias en Sevilla. Estos dos personajes, muy atinadamente, entablaron pláticas e interrogatorios con el franciscano y con el embajador, para ese momento ya ambos en España. Sus conclusiones fueron en el sentido de procurar mantener una buena relación con Japón para poder contrarrestar la creciente influencia de holandeses e ingleses en aquel Reyno. En esta forma se buscaria conservar una clara posición en aquellas tierras, sin motivar una abierta expansión de la evangelización para no despertar sospechas y mantener abiertas las puertas de las relaciones entre ambos reinos. ${ }^{24}$ Varte recomendó también que el rey recibiera al embajador y le diera el trato que le correspondía como enviado de un emperador poderoso. Su presentación en la corte al parecer se retardo, o cuando menos, hasta febrero de 1615 , el embajador japonés no había expresado abiertamente sus encargos y la respuesta real tampoco se había dado. Para esas fechas la estancia prolongada del séquito japonés se convertía ya en una carga al erario real y una molestia evidente para los religiosos que les hospedaban. Se les había alojado en el convento de San Francisco en la villa de Madrid y se les proveía, con cargo a la corona, de 200 reales diarios; el Consejo de Indias tomó la decisión de abreviar su estancia para también acortar los gastos y hacer posible su salida en la flota del año de 1615. Para lograrlo se enviaron repetidas comunicaciones a la corte con el fin de terminar el asunto y proveer el viaje de regreso. Dado que las respuestas se retrasaban, fue necesario pedir a la caja real de la Nueva España el envío de 20000 ducados para cubrir al convento madrileño de San Francisco los gastos que se habían originado y que se seguirian produciendo hasta el embarque en la flota del affo siguiente de $1616 .{ }^{25}$ Como dato curioso incluimos aquí que

\footnotetext{
24 AGI., FILIPINAS 1, R.4, fols.224 y 232.

25 AGI., FILPINAS 1, R.4, fol.237.
} 
la estancia del séquito japonés después de seis meses de permanencia en dicho convento, fue ya abiertamente rechazada por los religiosos, aduciendo, no sólo el daño efectuado en los aposentos, pero principalmente la inconveniencia de su alojamiento, ya que ocupaban las instalaciones de la enfermería y cuartos adjuntos, ocasionando que algunos de los enfermos, no atendidos debidamente, hubieran fallecido. El prior del convento rogó encarecidamente fueran trasladados los molestos huéspedes a otra casa. $^{26}$ Esto ya no fue necesario pues la embajada, acompañada siempre del franciscano, se encaminó a Roma en septiembre de 1615 a dar obediencia al papa. Para efectuar el viaje la corte les otorgó 4000 ducados. Fray Luis de Sotelo, el embajador y acompañantes regresaron de la visita papal hacia el mes de marzo de 1616, siendo prevenidos por el embajador español en Roma de evitar su paso por la corte madrileña y encaminarse directamente a Sevilla para embarcarse en la siguiente flota a la Nueva Espafia. El franciscano, quien presentó ante el papa las peticiones que no le fueron aprobadas en la corte espaniola, fue reconvenido por el Consejo de Indias y se le conminó a salir del reino espantol a la mayor brevedad. De acuerdo con la documentación de este caso, el embajador japonés y, desde luego, el franciscano, utilizaron una serie de disculpas para no embarcarse en la flota de ese año. En primer lugar se rechazo la partida por carecer de los despachos reales dirigidos al emperador japonés, resuelto este aspecto, adujeron después, enfermedad del embajador y por lo tanto imposibilidad para realizar el largo viaje. Consiguieron su propósito de permanecer más tiempo en España; sin embargo, gran parte de su ś́quito pudo ser enviado por el presidente del Consejo Real en una de las naves de la flota que se había retrasado. El embajador y el franciscano permanecieron en un convento cercano a Sevilla, prometiendo no ocasionar más problemas. ${ }^{27}$ Para junio de 1617 continuaban en Sevilla y el Consejo de Indias insistió en que, sin ninguna disculpa, fueran embarcados con toda decencia en la siguiente flota para la Nueva España y limitar sus gastos a un máximo de 600 ducados. El franciscano insistió aún en permanecer hasta el siguiente afio, precisamente por no disponer de medios financieros para efectuar tan largo viaje y con ello arriesgar sus vidas. ${ }^{28}$ No existen nuevas referencias tocantes a la embajada, de donde se podría suponer que efectivamente partieron para la Nueva España en la flota del affo de 1618. 
Es esta la última referencia ligada a la importante embajada japonesa, su destino y vuelta a la Nueva Espafia no la encontramos aún documentada.

Como consecuencia de la pérdida de las relaciones comerciales con el imperio japonés, la corona espanola volvió de nuevo sus ojos a la colonización, particularmente de la península de Baja California, en un intento de establecer puertos de resguardo y de iniciar la postergada explotación de recursos naturales. Las Relaciones y cartas de Vizcaíno referidas a su viaje al Japón, fueron, sin duda alguna, decisivas para el cambio de la estrategia colonizadora de Espaffa a partir de la segunda década del siglo XVII.

En sus postreros años Vizcaíno retoma su anhelo juvenil, la explotación perlífera en California. No logra la autorización real para su empresa; sin embargo, colabora estrechamente con quienes sí obtuvieron el permiso. Se trata de los Cardona, Nicolás y Tomás.

\section{LAS EXPLORACIONES Y DESCUBRIMIENTOS DE SEBASTIAN VIZCAÍNO}

\section{El primer viaje, La jornada de las Californias}

De la larga, contrastada e intensa vida de Vizcaíno, para los fines del presente trabajo, la atención se centra en los dos viajes a las costas de la Baja y la Alta Califomia. Fueron la gran empresa que aportó los nuevos conocimientos científicos sobre la región y que, por un lado, a partir del segundo viaje, diera origen al retomo a la inicial y equivocada concepción insular de la California. Por el otro, contribuiría a la nueva etapa exploratoria que se caracterizo por su índole mercantil.

Después del quinquenio de receso en el apoyo a los viajes por las costas del noroeste, que se produjo durante el primer periodo del gobiemo de Luis de Velasco hijo, el nuevo virrey recibió encargo real de reanudar dichas exploraciones. Los motivos para una y otra actitudes ya fueron comentados párrafos arriba. Don Gaspar de Zúñiga, conde de Monterrey, fue el virrey a quien correspondió tomar las decisiones finales para apoyar el primer viaje de Sebastián Vizcaíno, obedeciendo indicaciones precisas de Felipe II. Sin embargo, esta empresa no se dio desde su principio en forma declarada y abierta como viaje de descubrimiento y exploración, pasó por una fase previa, menos científica y más comercial.

Se inició al regreso de Vizcaíno de su primer viaje al Oriente, a las Filipinas en 1589, la experiencia que adquiriera en aquellas islas le proporcionaron relaciones y conocimientos acerca de las posibilidades de explotación de los recursos naturales de las Californias, fue así que su actividad principal durante esos primeros años se centró en el 
establecimiento de lo que él y otros compafieros consideraban un lucrativo negocio, el de las pesquerías en aquellas costas septentrionales del Mar del Sur. Para lograrlo presentaron petición formal ante el virrey y autoridades correspondientes de la Nueva España, mismas que forman un amplio legajo, Asiento y capitulacion del negocio de las Californias. ${ }^{29} \mathrm{Com}-$ prende, en su primer documento, lo referente al pleito con Hemando de Sanctotis, Antonio del Castillo y Pedro Lobato del Canto ${ }^{30}$ que se iniciara en tiempo del segundo virrey y fuera remitido a la corte en 1592. Dichos personajes tenfan licencia real otorgada el 29 de abril de 1587 por un tiempo de diez años para explotar, precisamente lo que deseaban incluir Vizcaíno y sus compañeros. Después de un largo proceso, finalmente, el 25 de septiembre de 1593, la Real Audiencia determinó conceder la licencia a Vizcaíno y copartícipes, y a partir de esa resolución, se incluye un extenso documento que corresponde al anteproyecto de Asiento y capitulaciones para la jornada de las Californias, celebrado en 1593 ante el escribano real, Antonio Gallo. ${ }^{31}$ A través del análisis de la fuente se conocen las peticiones que limitaban los derechos y obligaciones de los contratantes: Vizcaíno, Gonzalo Rodriguez Calvo, Juan de Valencia de Peña, Diego de Torres Navarro y otros y que constituye información preliminar tocante a esta primera jornada de descubrimiento a las Californias. Las peticiones y decretos aprobatorios, resumidamente expuestos, permiten conocer los detalles de la formalización de un viaje de esta magnitud. Durante la primera parte del asiento se les concedfan las siguientes peticiones: El navío San Bartholomé que estaba en el puerto de Acapulco, se les otorgarian del almacén armas: 100 arcabuces, 20 mosquetes y 150 arrobas de polvora, la jarcia y clavazón y otras cosas para el viaje, se les concedería mediante el debido pago en un plazo de dos afios y se nombrarla por capitán a Sebastián Vizcaíno. Los miembros encargados del viaje solicitaron el acompañamiento de religiosos franciscanos, solicitud que se tumó al comisario correspondiente. Llevarfan consigo indios y naturales solteros a los que se comprometerían a pagarles su trabajo. En cuanto al costo de la empresa, se solicitaría un préstamo a la caja real de 12000 pesos de oro común pagaderos en ocho affos o menos.

Sin embargo, dificultades entre los componentes de la compañla pospusieron el inicio del viaje y las condiciones del mismo se modificaron paulatinamente, hasta llegar al Asiento y capitulaciones definitivas que corresponden a las del año de 1596 y que tuvieron la aprobación real, dada

30 AGL., PATRONATO, 30, R.L.

30 AGI., PATRONATO, 30, R.1. fol.15.

31 AGI., PATRONATO, 30, R.1. fol.41. 
en el Bosque de Segovia el affo de 1593, que establecía la condición de su inicio sólo tres años más tarde, el día 10. de marzo de 1596 y con una validez por veinte affos. ${ }^{32}$ Fue así como lo que inicialmente se planeó como una empresa preponderantemente comercial, se transformo en el primer viaje de las Californias, ya durante el periodo institucional de la corona espafiola, con un claro y múltiple objetivo: exploratorio, poblacional y comercial.

Existe la solicitud del entonces aún capitán Vizcaíno al rey, la que firmó en la ciudad de México el 5 de noviembre de 1597:

S.V. pide ser ayudado de parte de su Mag. para hacer la jornada de las Californias, habiendo de salir del puerto de Acapulco por el mes de marzo del año que viene del noventa y ocho y lo que se ofrece al llevar, así de gente y navíos, pertrechos de guerra, buzos, rastreos para las pesquerías de las perlas y gente para hacer el descubrimiento que lo que pretendo es lo siguiente. ${ }^{33}$

Inserta una larga y detallada lista de requerimientos, iniciándola con 15000 pesos de las cajas reales y continuada con los pertrechos para las naves, la gente requerida de mar y guerra, entre ella algunos buzos, las armas y municiones, bastimentos para la gente, harina, habas, garbanzo, tocino, cecinas, vinagre, aceite y otras legumbres, ornamentos para celebrar el culto divino, vino para que los frailes celebraran el oficio divino. Asimismo menciona la existencia en la costa de los dos navíos necesarios, el San Francisco y el Jusepe. ${ }^{34}$

Este difícil y problemático viaje está bellamente narrado en una de las dos versiones de la Relación escritas por el propio capitán Vizcaíno. ${ }^{35} \mathrm{Su}$ autor lo inicia con una suscinta enumeración de las leguas que hay entre cada uno de los puntos costeros que recorrió, primeramente desde Acapulco hasta Salagua en una distancia de 100 leguas, de Salagua a Cabo Corrientes, 60 leguas y así sucesivamente hasta el cruce, a través de la Ensenada y boca de la California que podrá tener de travesía, ochenta leguas. Pasa después a describir la naturaleza de los parajes, los encuentros con los naturales, la toma de posesión y la denominación general de la provincia como la Nueva Andalucía, la permanencia en cada sitio y los

\footnotetext{
${ }_{32}^{32}$ AGI., PATRONATO, 20, R.17, N.5.,fols.1-96.

33 AGI.,GUADALAJARA, 134.

34 AGI.,GUADALAJARA, 134, fols. 912-913.

35 AGI, GUADALAJARA, 133: Relación que Sebastián Vizcaíno a cuyo cargo fue la Jornado de las Californias desde el Puerto de Acapulco hasta paraje de veinte y nueve grados de la Ensenada de las Californias a la parie de noroeste que es desde donde se volvió por no poder pasar adelante por el tiempo ser contrario y habérsele quebrado los hierro del timón con una tormenta y lo que vib en la tierra y mar y entiende de la jornada es lo siguiente:
} 
nombres que les adjudicó, entre otros: al puerto, San Felipe y a cada una de las dos islas, San Francisco y San Sebastián. Narra las dificultades de la navegación, en especial por la presencia de los bajos y las corrientes en la ensenada a la que nombró de $L a P a z$, por haberle salido a recibir muchos indios con regalos de pescados, frutas, conejos, liebres y venados. En ese sitio se construyó un fuerte en donde dejó la nave capitana y a la gente casada al mando del capitán Diego de Figueroa. Continuó el viaje el día 3 de octubre de 1596 a bordo de la almirante y con la lancha, cabo adentro, o sea por el mar o golfo de California, hasta los 27 grados. A esa altura volvió a recibir la visita pacífica de los indígenas; sin embargo, se suscito un serio incidente entre marineros y naturales, al haber golpeado involuntariamente uno de los soldados en el pecho a uno de los naturales, quienes respondieron violentamente y obligaron a los españoles a embarcarse. En la refriega se volcó la chalupa ya que los soldados no pudieron guardar el equilibrio ante el ataque de los indígenas desde la orilla. La pérdida de esta embarcación, indispensable para poder llegar a tierra y abastecerse de agua, obligó al grupo a retornar al puerto de $\mathrm{La} P a z$. Frente al mal tiempo y al inicio del invierno la gente pidió al capitán regresar a la Nueva España, ya que resultaba imposible continuar el avance, no sólo se había perdido la chalupa, también la nave capitana, la San Francisco, estaba en mal estado. Ante esta sítuación Vizcaíno accedió y envió de regreso a una parte de la gente, quedándose con la San Jusepe y con cuarenta hombres de mar y guerra, los más bien intencionados para entrar por la dicha ensenada a descubrirla del todo. ${ }^{36}$

Continuaron su viaje el 28 de octubre de 1597 y navegaron con tormentas y vientos contrarios durante 67 días a lo largo de la costa interior de lo que el capitán llamó la boca o sea el golfo de las Californias hasta subir a una latitud norte de 29 grados, desde donde tuvieron que regresar pues, inclusive, se le quebraron los hierros del timón. De nuevo, ante este hecho y el temor a un ya muy próximo invierno, se dirigieron hasta las islas de Mazatlán.

Prosigue su Relación al verter su opinión sobre varios aspectos:

a) La importancia de volver a esas tierras por las enormes posibilidades que ella brindaba en recursos perlíferos, anexó la muestra de las perlas que los indígenas le obsequiaron e inició con ello la difusión de ese tipo de riquezas;

${ }^{36}$ AGI. Guadalajara 133: Relación que Sebastián Vizcaíno a cuyo cargo fue la Jornada de las Californias desde el Puerio de Acapulco hasla paraje de veinte y nueve grados de la Ensenada de las Californias a la parte de noroeste que es desde donde se volví́ por no poder pasar adelante por el tiempo ser contrario y habérsele quebrado los hierro del timón con una tormenta y lo que vio en la tierra y mar y entiende de la jornada es lo siguiente: 
b) La variedad de peces en sus aguas costeras, sardinas, atún y caballas;

c) La existencia de salinas y la posibilidad de encontrar oro tierra adentro; $y$

d) La gran cantidad de naturales de diferentes niveles culturales, todos muy aptos para ser evangelizados.

Concluida esta segunda versión de su primer viaje, incluye en ella la solicitud de requerimientos para poder continuar estos descubrimientos y las mercedes que para sí y sus hijos requería. Este documento está fechado el 8 de noviembre de 1607 y lleva la firma autógrafa del, para ya entonces, general. Lo que Vizcaíno relató se encuentra confirmado por los testimonios rendidos por algunos participantes en esa jornada, quienes fueron presentados en el proceso de Información correspondiente al general Vizcaíno.

Entre estos testigos tenemos al piloto mayor de la armada, Francisco de Bolaños y al alférez real, Pedro López de Contreras, quienes participaron en ese primer viaje de Vizcaíno, la llamada Jornada de California. Ambos coinciden en sus testimonios al relatar la salida desde Acapulco y Salagua en tres navíos, uno de ellos de más de 500 toneladas, y los tres muy bien pertrechados de bastimentos, armas y municiones, caballos y ganado. Los miembros de este viaje fueron entre 400 y 500 personas, tanto hombres casados con sus mujeres como de mar y guerra. Se reclutaron en su mayoría en México y Puebla de los Ángeles; 400 partieron desde esas ciudades hasta el puerto de Acapulco y dos companías más, alrededor de 100 hombres, llegaron directamente a Salagua, todos los integrantes abastecidos con cargo al general. ${ }^{37} \mathrm{El}$ alférez proporciona interesante narración de esta jornada, al describir el desembarco en las costas de Mazatlán para abastecerse de agua y alimentos, así como la llegada al puerto de La Paz, el recibimiento pacífico y cordial de los naturales, la toma de posesión de dicha tierra, la construcción de una iglesia y celebración de oficios divinos. La necesidad de devolver la capitana, San Francisco, al puerto de Acapulco por haber sufrido una avería y la continuación del viaje con la almiranta.

Interesante es el testimonio de fray Andrés de la Asunción, presbitero profesor de la orden de Nuestra Señora del Carmen de los Descalzos y comisario del viaje del descubrimiento de las Californias desde Acapulco hasta el Cabo Mendocino; no debe ser confundido con el experimentado religioso de la misma orden, fray Antonio de la Ascención, quien desempefará especial papel en la decisión de continuar las exploraciones a las

37 GUADALAJARA 133, fols.14-15. 
Californias, años más adelante. Afirma fray Andrés que el general se previno y enarbolo estandarte real y banderas de infanteria en la ciudad de México con el fin de levantar gente, a lo que respondieron poco más o menos 450. En Acapulco se previnieron dos navios grandes, una fragata y una barca con todo lo necesario.

A partir, tanto del análisis del documento arriba descrito, como de la primera versión de la Relación que ha sido comentada en la obra fundamental escrita por don Álvaro del Portillo y también revisada en fuente primaria por los autores de este trabajo, aquí solamente mencionaremos sus resultados generales y especfficos, acordes al objetivo de nuestro proyecto de investigación, las aportaciones científico-técnicas de las expediciones septentrionales durante los siglos XVI, XVII y XVIII novohispanos.

La exploración se dedicó, fundamentalmente, a recorrer las costas interiores, las de la boca del mar, hasta la altura de la Isla del Ángel de la Guarda, sus logros fundamentales radicaron en:

a) El restablecimiento del inicial poblado en el mismo sitio que lo fundara Cortés, en Santa Cruz, ahora denominado por Vizcaíno con el nombre que se conserva hasta la actualidad, La Paz.

b) La demarcación detallada de la costa con el señalamiento de buenos puertos naturales, la descripción de un terreno costero poco atractivo por sus tierras inhóspitas, pero rico en perlas, en salinas y en peces. $\mathrm{La}$ existencia de abundantes bosques que podrian proporcionar madera para la reparación de las naves y el probable y presumible extenso territorio interior con minerales preciosos y buenas tierras donde se cultivaba maíz y se criaban animales.

c) La presencia de una población aborigen que debería ser evangelizada y que, con buen trato, fácilmente incorporable a la cultura occidental.

Más que los pocos resultados materiales de este primer viaje, fue el comportamiento de Vizcaíno durante las difíciles jomadas y su atinado proceder al reconocer su fracaso, lo que le mantuvo el favor real. Los documentos que redactó, su Relación y las cartas sucesivas, mantuvieron el interés real en la presencia espafiola en las Californias. En ellos manifestó los objetivos que tan acertadamente supo combinar al darles relevancia al aspecto material y al espiritual como las motivaciones que deberian guiar los subsecuentes viajes californianos y que, respondian a los mismos intereses vigentes en la política expansionista oficial.

La perseverancia de Vizcaíno por las Californias se manifest 6 desde las propuestas que formuló al final de su Relación de este primer viaje y que sentarian las bases para el siguiente. Fueron aceptadas por el rey, pero la buena suerte no fue siempre compañera de Vizcaíno, ya que la muerte de Felipe II suspendió temporalmente el interés en las expediciones. 


\section{El segundo viaje a las Californias y su carácter de empresa científica}

El peligro ante la amenaza de ingleses y holandeses, quienes pretendían encontrar el paso de Anián y habían demostrado sus posibilidades de ataque y de disputa de la hegemonía marina en el Pacífico, fue el motivo decisivo que inclinó al cambio político oficial. El nuevo rey, Felipe III, decidió la continuación de los viajes al septentrión marino, pero dio precisas instrucciones a fin de limitar los objetivos exclusivamente a la exploración geográfica de las costas externas, sin incluir el Mar de Cortés y sin perder el tiempo en aspectos comerciales.

Aparece aquí, por primera vez en forma explícita, una finalidad que, según del Portillo, puede considerarse ya de carácter científico. Las razones para ello radican en la dedicación y cuidado con que se preparó la expedición, en las detalladas instrucciones que se elaboraron para su observancia durante el viaje, en la selección de los miembros directivos y en la contratación de expertos militares, navegantes, pilotos y cosmógrafos.

Su carácter de empresa científica se manifiesta ya desde las Instrucciones oficiales enviadas a los capitanes y formuladas acordes con las directrices de la política en materia de exploraciones. Como era de esperarse no coinciden totalmente con los intereses y objetivos del propio Vizcaíno, a pesar de ello, el navegante tenía que acatarlas si deseaba llevar a cabo su empresa. De acuerdo con las Instrucciones el objetivo central fue:

el descubrimiento y demarcación de los puertos, bahías y ensenadas que hay desde el cabo de San Lucas, que está en 22 grados y un cuarto, hasta el cabo Mendocino, que está en 42 grados, costa de noroeste sureste...os mando que no enviés ni consintáis entrar en ningún puerto gente tierra adentro, en busca de indios, ni a saber si los hay, porque para el negocio e intento principal no es necesario... ${ }^{38}$

El mismo documento señala claramente el aspecto científico al instruir puntualmente acerca de las observaciones, anotaciones y reconocimientos náuticos, marinos, cartográficos y geográficos. Para el cumplimiento de estos cometidos científicos participaron especialistas de experiencia, entre ellos el más destacado y ampliamente citado en la Instrucción, el cosmógrafo Gerónimo Martínez Palacios, de él y sus tareas se dice:

...informado de larga experiencia que tiene de mar el capitán Gerónimo Martínez Palacios, y de la inteligencia que tiene de matemáticas y de la buena mano que tienen las perspectivas que hace 38 AGI., GUADALAJARA, 133: Instrucción dada a Sebastián Vizcaíno para el viaje de 1602
y Del Portillo, A. (1982:346ss.) 
y de cuán práctico es en hacer cartas de marcar generales y particulares e informado por lo que Su Magestad le encargó cerca de su personas y de personas prácticas en las cosas de mar, le nombró cosmógrafo de esta jornada... se le den los pergaminos necesarios para que él los entregue, lineados, a los pilotos y sus ayudantes para que vayan señalando todo lo que fueren viendo muy precisamente.. ${ }^{39}$

Se encomendó el reconocimiento de las bahías, pero limitado sólo a sus entradas y de algún puerto de abrigo, sin detenerse al pormenorizado de sus posibles muchas entradas, esteros y puertos pequeños. En cuanto a las islas se hizo especial mención en su ubicación exacta, su distancia con respecto a tierra firme, sus posibilidades de puerto y el reconocimiento de la costa norte en el viaje de ida y de la contraria en el regreso. Otro de los aspectos científicos fue la recomendación de observar los eclipses que se pudieran presentar durante el viaje, procediendo a todas las anotaciones posibles en relación con cualquier fenómeno de esta índole.

Uno de los aspectos más destacados incluidos en la Instrucción y que fue puntualmente observado, es el que se refiere a la conveniencia y necesidad de celebrar Juntas con la participación de diferentes miembros de la expedición. En ellas se deberían discutir los aspectos de la navegación, las rutas a seguir, los reconocimientos y demarcaciones, así como batallas si fuere el caso. La insistencia en la celebración de las juntas es interesante, ya que da a la expedición un toque democrático y, fundamentalmente, le aporta modalidades comunicativas y de interacción.

\section{APORTACIONES CIENTÍFICAS COMO RESULTADO DEL SEGUNDO VIAJE}

Los documentos: Actas de las Juntas celebradas por los capitanes, pilotos y cosmógrafo, durante la segunda navegación de Sebastián Vizcaíno a California (1602), ${ }^{40}$ la Instrucción dada a Vizcaíno con fecha del 31 de mayo de $1602,{ }^{41}$ el Derrotero de la navegación desde el puerto de Acapulco al Cabo Mendocino y boca de las Californias hecho por el capitán Gerónimo Martín Palacios, ${ }^{42}$ los tres Pareceres de fray Antonio

39 AGI., Guadalajara 133: Instrucción doda a Sebastián Vizcaino para el viaje de 1602 y Del Portillo, A.(1982:348ss.).

40 AGI., MÉXICO 372.t.Actas hechas por el escribanodon Diego Campos Piego de Santiago de las Juntas celebradas por capitanes y pilotos.

41 En AGI., GUADALAJARA 133.

42 En AGI., MÉXICO 372, fols.47-58v., los 32 mapas de Enrico Martínez en Mapas y planos-México 53. 
de la Asunción ${ }^{43}$ y su Derrotero Cierto y Verdadero para navegar desde el Cabo Mendocino que es desde altura de 42 grados hasta el puerto de Acapulco por la costa de la Mar del Sur... ${ }^{44}$ son los documentos que han proporcionado los materiales para el análisis de los resultados cientificos de la expedición. De su consulta y estudio hemos derivado las siguientes aportaciones científicas, objeto central de este trabajo.

1) Las descripciones de las costas, litorales, ensenadas, islas y demás accidentes geográficos, por su exactitud en la narración, constituyen una indudable aportación científica para el conocimiento de la zona. Fueron el material básico para la elaboración final de los dibujos a cargo del destacado científico, Enrico Martínez.

Estos mapas, ampliamente reproducidos en varias obras de diferentes épocas, fueron inicialmente bosquejados in situ por el cosmógrafo principal de la expedición, Gerónimo Martín Palacios. De acuerdo con don Álvaro del Portillo, una vez de regreso en la capital novohispana, le fueron entregados a Enrico Martínez para su reelaboración. Es esta la versión que ha llegado hasta nosotros y que ha sido considerada por la gran mayoria de los estudiosos de ese viaje, como los más exactos y de mayor seguridad científica elaborados en esa época. Se trata de un conjunto de 36 planos de demarcación de los diferentes puertos, ensenadas, islas, sectores de las costas, puntas, bahías, cabos y perfiles de costas y serranías. En cada uno de ellos está anotada la toponimia que, en la mayoría de los casos, se conserva hasta la actualidad. Importante es este aspecto que representa, sin duda alguna, uno de los iniciales aportes a la identidad regional, ya que los signos çartográficos forman parte de los elementos simbólicos materiales de la identidad.

Con referencia a la toponimia establecida por Vizcaíno se ha argumentado que modificó la previamente anotada por Rodríguez Cabrillo; sin embargo, se ha comprobado que no fue así, pues Vizcalno no conoció, ni recibió esa información. Como es usual en el comportamiento de los polf́ticos, hay la tendencia a olvidar las aportaciones de sus antecesores y a considerar como lo único importante lo que cada mandatario propone, auspicia o realiza. Al parecer esta actitud ya era

\footnotetext{
43 El primer Parecer del 20 de mayo de 1629 fechado en el Convento de Carmelitas de Valladolíd en AGI., PATRONATO 30, R.1, fols.140-153; el segundo Parecer del 8 de junio de 1629 desde el mismo convento de Valladolid, fols. 140-153; el Segundo Parecer del 8 de junio de 1629 desde el mismo convento de Valladolid, fols. 162-190 y en Museo Naval de Madrid, Navarrete, tomo 19, pp. 423-26 y el tercer Parecer del 22 de marzo de 1632 escrito desde el Convento de los Carmelitas Descalzos de la ciudad de Puebla de los Ángeles, en Museo Naval, Navarrete, tomo 19, pp. 463-476.

En Biblioteca Nacional de Madrid, Ms.3203.
} 
usual en aquella época, puesto que se habian olvidado las aportaciones realizadas medio siglo antes.

2) En estrecha relación con el aspecto geográfico son de enorme importancia las descripciones y el trabajo cartográfico de fray Antonio de la Ascención. Su repercución más inmediata lo fue en la cartografia, a fray Antonio se debe la introducción de uno de los errores más significativos en la representación cartográfica de la época. A partir de su descripción y elaboración de un mapa de las costas recorridas, se retornó a la inicial concepción de California como una isla, olvidándose, de nuevo, todas las aportaciones que habían logrado, tan acertadamente, los exploradores anteriores.

¿Cómo es que se propició esta equivocación? El propio fraile la introdujo a través de sus repetidos escritos y del mapa que, según sus propias palabras, realizó, Sabemos que, además de su misión evangelizadora, llevaba el encargo del propio virrey de fungir como segundo cosmógrafo y en esa calidad representó gráficamente lo que se descubrió durante la travesía. Al respecto sus palabras son:

\begin{abstract}
...A mi me encarg 6 dicho Virrey fuese haciendo oficio de cosmógrafo en este descubrimiento, no obstante que iba otro cosmógrafo nombrado por S.M. para el dicho efecto...De los sucesos de este descubrimiento y de lo que se descubrió, hice una relación, y pinté una tierra por sus rumbos y costas, con sus alturas para que sirviese como por carta de marear para aquella costa, de que se ha enviado copia a S.M.... ${ }^{45}$
\end{abstract}

Además de la representación gráfica, fray Antonio mencionó en sus varias versiones sobre la expedición, la existencia del "estrecho de Anián" que se iniciaba en el extremo septentrional de aquellas tierras que habían descubierto. Paralelamente retoma la ubicación de una de las "Siete Ciudades", la de Quivira; algunos de sus textos dicen:

...se da principio a un brazo de mar, que se llama mar de California, o mar Bermejo que entra hacia el norte entre el reino de la Califomia y las costas de la Nueva España, que tendrá de travesía no hay cien leguas, tengo por ciento que se comunica este mar en el estrecho de Anián y por él al Mar del Norte, por donde se puede dar paso y navegación que si así fuera de harta importancia el estar descubierta y porque por ella se podía encaminar la plata del Pirú y de esta Nueva

\footnotetext{
45 Primer parecer de fray Antonio de la Ascención sobre expediciones de descubrimiento y colonización en California en Valladolid de México, 20 de mayo de 1629', AGI., PATRONATO 30, R. 1, fols.140-153.
} 
Espefia que se envis a Esporin todos los afios en caso de que el enemigo holandea quiera ponerse en el peso de La Habanu pare coger las flotes, tal como lo hizo el affo pasado, $y$ intenta, segin dicen, hacer eate affo lo mismo...

sabrase si este brazo de mar se commica con el Mar del Norte o por el estrecho de Anifn y si por el se puede hacer navegación a Espatha que sería de muy grande importancia descubrir por aqu nueva navegación para Castilla pana aprovecharse de ella en caso de mucha necesidad..4

3) Tanto las noticias redactadas como las dibujadas por fray Antonio fueron de una, relativamente, rápida difusión puesto que a poco tiempo de su registro se encuentran plasmadas en la cartografia mundial. De acuerdo con don Miguel Leon-Portilla la más temprana y directa alusión a esas informaciones procede de un mapa de América del Norte que se publico en Londres en 1625. Fue disefiado por el profesor de astronomía en Oxford, Henry Briggs, quien tenía un muy especial interes en la localización del estrecho de Anián, puesto que inclusive escribió un Breve discurso sobre el tema. En el texto que acompana al mapa se alude, ya explícitamente y probablemente por primera vez en ese momento, a la insularidad de la California y se proporcionan datos que, sin duda alguna, procedieron de las narraciones de fray Antonio.

A partir de este mapa se localizan numerosas representaciones en las cuales aparece California como isla, el error se mantiene hasta bien entrado el siglo XVIII. Sin embargo, también hay pruebas de que no todos los estudiosos de la época aceptaron la insularidad, algunos de ellos conservaron la idea de la peninsularidad y la representaron así.

El clima sociocultural aún prevaleciente a finales del XVI favorecio la permanencia de una mítica geograffa sobre el septentrion. Fue así como vemos intensificarse la concepción acerca de la existencia del estrecho de Anián, paso geográfico favorable a los intereses económicos y políticos de la corona española. Observamos que revive la leyenda de las Siete Ciudades al introducir en las descripciones la ubicación de Quivira. Lo mismo sucede con la de la mítica reina Califomia que va ligada a la insularidad de su reino. Estas modalidades de carácter fantasioso son, fundamentalmente, producto de los escritos varios de fray Antonio. De nuevo aquí la participación en la persistencia de aspectos míticos de un religioso, ya había sucedido afios antes con fray Marcos de Niza.

46 AGI., PATRONATO, 30,R. 1: Fray Antonio de la Ascención en su Primer Parecer.

47 AGl., PATRONATO 30, R.1, fols.140-153; el Segundo Parecer del 8 de junio de 1629. 
Algunas de las explicaciones que al respecto podemos manejar se basan en la influencia del objetivo misional. En el afán de despertar un mayor interés oficial en la población de esas remotas regiones y con ello asegurar la labor evangelizadora entre sus aborígenes, los religiosos no titubearon en ponderar, encomiar, exagerar y aún fabular las condiciones geográficas favorables para lograr su fin. En el caso del personaje que aquí nos ocupa, la introducción de estos aspectos míticos va unida a sus acertadas aportaciones cientificas. Al respecto contamos con el comentario de Del Portillo, quien considera que la obra del religioso carmelita es en su conjunto de suficiente veracidad critica, de recto espíritu y de honradez histórica. Si bien se transparente su deseo de mover al rey a que ordene de una vez la ocupación efectiva de California. (Del Portillo, 1982:202).

Una más de las aportaciones al conocimiento científico que procede de los escritos de fray Antonio se vincula estrechamente con la crónica sobre los recursos naturales y los humanos, esta última sin carácter de descripción etnográfica.

4) Por lo que se refiere al primero de los recursos a lo largo de sus Pareceres y de su Relación, el carmelita describe las riquezas naturales de la región en sus diferentes modalidades: fauna, flora, suelo y minerales. Destaca por las reiteradas y entusiastas menciones a la fauna marina, su existencia es descrita a lo largo de la travesía, insistiendo en su abundancia en algunas costas, particularmente las de la porción meridional de la península. No pasó por alto al observador fraile la presencia de las ballenas y los lobos marinos.

Las citas sobre la existencia de especies marinas incluye las siguientes denominaciones vulgares: chernas, pargos, meros, corvinas, cazones, otollos, esturiones, lisas, salmones, atunes, rayas, chuchos, caballos, roncadores, bonitos, dorados, lenguados, mantas, ostiones, barbetos, puercos, lagartijas, sirgueros. Dice al respecto fray Antonio:

...hay en este mar muchas diferencias de peces chicos y grandes, de algunos pondré aquf sus nombres por ser peces conocidos en otros mares que yo cogf y tuve en mis manos y comf de ellos para que se entienda la abundancia, bondad y fertilidad de aquel mar... Estos pescados son de buen gusto y sabrosos y sanos... (Del Portillo, 1982:402).

Por supuesto que concede atención a lo que más tarde sería uno de los motivos de nuevas expediciones hacia el sur de la península, la posibilidad de la extracción de las perlas a lo largo de los dos litorales. Menciona la existencia de muchos comederos de ostiones en donde se crian las perlas; de su elevado número y de la buena calidad y tamanio de las que se podrian 
extraer de los esteros. Localiza éstos desde la punta de San Lucas hasta una altura de 36 grados. Cuando busca justificar la necesidad de poblar la zona, emplea como uno de sus argumentos la riqueza que podría proporcionar a los colonos la explotación de los ricos mantos de ostiones.

Además de la fauna marina hay también descripciones de la terrestre. Consideró fray Antonio que las tierras cercanas a cabo San Lucas eran muy propias para criar ganado vacuno y con ello fomentar la colonización. Mencionó que en sus montes había gran cantidad de especies de caza de monte, como conejos, liebres, venados, leones, tigres, armadillos, codornices y palomas torcaces. A la altura de la actual Bahía Magdalena se asombró el cronista de la: "multitud que hay de varias aves y pajaros que causa espanto y admiración ver tanta multitud y variedad," (Venegas, 1943:43).

Frente a las costas de Ensenada, Tijuana y San Diego, reportó la presencia de gran cantidad de gansos, ánsares blancos y grandes patos, codomices, liebres y conejos. Más al norte, a la altura del puerto de Monterrey, además de los animales menores, la fauna que se consignó pertenecia a las especies mayores: grandes osos, antas, ciervos y venados. La descripción de algunos de ellos cae, ligeramente, en lo fabuloso.

Por lo que se refiere a la flora y la calidad de la tierra también es frecuente y detallada su descripción de acuerdo con las diferentes zonas climáticas que recorrieron. Generalmente el interés que guiaba la observación de la flora y del suelo estaba en función de la localización de agua y leña destinados al abastecimiento de la expedición y de la posibilidad de cultivos para el asentamiento de la futura población. El elemento esencial de sobrevivencia era el agua, de aquí que la referencia a su obtención sea muy frecuente. En la mayoría de los casos era a través de pozos como se surtían de ella, generalmente su localización dependía de la información que les querían proporcionar los indígenas habitantes de cada lugar, lo que llevaba también a iniciar la interacción con ellos a partir de la necesidad de reabastecerse del agua. Simultáneamente a las descripciones de los sitios en que se localizaban los pozos, arroyos o lagunas, incluye fray Antonio las que corresponden a la tierra o suelo. Se trata de observaciones generales cuyas expresiones giran en tomo a conceptos relacionados con la calidad del suelo, algunos ejemplos son ilustrativos: tierra fértil y llana, tierra muy estéril, es tierra de buen temple y muy fértil y abundante en muchos y varios árboles, muchas dehesas de buenos pastos, está toda la tierra de este reino dentro de la zona templada que cae a la parte norte y pasan por encima de ella varios climas. Algunos de los ejemplares de la vegetación que se encuentran citados son: álamos blancos y negros, sauces, zarzas, carrizales, juncos, mimbres, higueras, mangles, 
lentiscos y ciruelos. Extrañamente no se hace referencia a los diferentes tipos de cactáceas, tan característicos de la península de la Baja California.

Los recursos minerales de la zona están referidos sólo tangencialmente. Especial atención produjo en fray Antonio la existencia, a la altura de la Isla de Cedros, en tierra firme, de una serranía pintada y paspeada de muchos y varios colores, con unas vetas y cintas, que aquella sierra era toda de minas y que había grandísima riqueza de plata y oro.

Fray Antonio en su objetivo de propiciar la población de la región, sugiere que se debería poblar la tierra que se localiza frente al puerto del río del Tizón para que todos puedan gozar de las pesquerías de perlas y de la riqueza de metales. Consideró al actual valle de Mexicali, a lo largo del río Tizón, el actual Colorado, como territorio perteneciente a Nuevo México y no a Califomia. En éste localizó la existencia de una laguna del Oro y numerosos poblados, en tanto que sobre la costa de California la riqueza consistía en montes con muchas minas de plata que podrían interesar a los vecinos, según el fraile carmelita, los pobladores del puerto del Tizón en Nuevo México. La posibilidad de la explotación minera estuvo ligada estrechamente con la fundación de nuevas poblaciones, muy en especial en las zonas septentrionales, en aquel momento, fronterizas entre los límites de la Nueva Espafia y las provincias a su norte, Nuevo México, Nueva Galicia y Nuevo Reino de León.

5) Una más de las aportaciones al conocimiento de la región costera septentrional de la península radicó en datos referidos a su población aborigen. Éstos, como en muchas de las Relaciones de la época y de la región, son descritos tangencialmente; en el caso que nos ocupa, las referencias son muy generales, es por ello que las hemos considerado, más que como datos etnográficos, solamente como información acerca de la existencia de naturales de esos territorios. Como ya mencionamos, la interacción entre los españoles y los indígenas se inició a través de la búsqueda del agua por parte de los extranjeros. Ligada a su localización iba el consumo de alimentos, eran los naturales quienes se acercaban a los españoles ofreciéndoles su pescado. En cuanto la relación se había iniciado, los indígenas surtian diariamente de pescado fresco a quienes consideraban como sus visitantes. En correspondencia éstos les obsequiaban con cosillas de poco valor, que, sin embargo,causaban alegría a los nativos. Fray Antonio observa a los habitantes y describe las características generales de ellos, su vestimenta e instrumentos, su estatura y constitución física.

Otro de los participantes en el segundo viaje, el conocido como Del Cabo Mendocino, el capitán Esteban Peguero, proporcionó también una detallada descripción de lo sucedido a lo largo del mismo, en especial en lo relativo a los recursos naturales de que se podían disponer para reabastecer las 
naves que provenían del Oriente, con especial mención de la buena disposición de los naturales de la región en proponcionar bastimentos de fruta y pescado frescos, así como de agua.

El aspecto humano que se deriva de la expedición se manifiesta en la meta colonizadora. Aquí fray Antonio sigue la actitud que le inspiro fray Bartolomé de las Casas y defiende la necesidad de abolir la encomienda. Sugiere al rey que si se desea tener éxito en el poblamiento de la región, deberá evitarse dar a los españoles la encomienda de indios. Desde luego que su preocupación principal radicó en la misión evangelizadora y en la obligación real de asegurarla aún a costa de grandes gastos, en especial cuando se tenía plena y confiable noticia de la existencia de reinos poblados de indígenas.

6) La última de las contribuciones al conocimiento cientifico que se puede extraer de la expedición y específicamente de los documentos que escribió fray Antonio, cae en el campo médico. De acuerdo con la revisión que hemos hecho de las Relaciones marítimas del siglo XVI, es ésta la única en la que se encuentra una detallada descripción del padecimiento tan frecuente en los largos viajes por mar, el escorbuto. Ante el cada vez mayor número de enfermos, que se acrecentaba a medida que transcurría el tiempo de navegación, y que, inclusive, obligó al envío de regreso a una de las naves, es muy probable que fray Antonio procediera a la descripción del padecimiento, Ésta se encuentra ampliamente detallada en la versión que debemos al historiador fray Juan de Torquemada y que según los estudiosos de los documentos, procede del trabajo de fray Antonio de la Ascención. El mismo fray Antonio, al comienzo de su relación resumida declara textualmente que la trae impresa el Padre fray Juan de Torquemada, de su 'Monarquía Indiana'. (Del Portilo, 1982:200). Con base en lo anterior es que consideramos aqui la descripción del padecimiento médico que tan graves dafios causaba a los marinos que participaban en largos viajes.

Al parecer la máxima incidencia de la enfermedad se produjo a la altura del puerto de Monterrey en la Alta California después de seis meses de navegación con sus interrupciones. Coincide aquí, según fray Antonio, con la misma que padecen los viajeros que vienen de China y quienes, a esa altura, llevaban en general, cuatro meses de recorrido, en este caso, ininterrumpidamente, y de la cual suelen morir la gran mayoría de los navegantes y pasajeros. De acuerdo al autor a esa altura geográfica corre un aire muy delgado y frío que traspasa a los hombres flacos...y debe traer consigo algo de pestilencia (Torquemada, 1975-85:71). Es precisamente

${ }^{48}$ AGI., PATRONATO 30, R.3. 
esta pestilencia la que afecta a los cuerpos cansados, flacos y molidos con el trabajo que hasta allí se padece. La causa se atribuye a la debilidad del organismo producida por el trabajo, no se tiene aún la noción de la verdadera etiología de la enfermedad.

Posteriormente se describen los sintomas del padecimiento, entre los que destacan los intensos dolores, las manchas y granos de la piel, los verdugones abajo de las rodillas que imposibilitan moveŕ las piemas, la inflamación de las encias que originaba la pérdida de dientes y muelas y con ello la dificultad para comer. ¿Coinciden estos síntomas con los conocidos para el escorbuto?

La consulta con los colegas médicos ${ }^{49}$ nos permite afirmar que la descripción contenida en el documento de fray Antonio corresponde, con bastante certeza, a un cuadro agudo, no sólo de deficiencia de vitamina C, también del complejo B. El dolor intenso que se describe con tanto detalle está relacionado, precisamente, con la falta de los componentes vitamínicos mencionados. La causa del padecimiento, como es ahora bien conocida, radica en la carencia de alimentos frescos; este era uno de los problemas fundamentales que se presentaba durante las largas expediciones marítimas de los siglos pasados. La dieta de los navegantes del siglo XV1 era sumamente precaria, la mayoría de los alimentos eran aquellos que se podían conservar fácilmente, carne seca, pan o bizcocho secos y algunos cereales que eran cocinados durante el trayecto. $\mathrm{El}$ acceso a los frutos y legumbres frescos era casi imposible, de aquí la importancia que concedían los espantoles a la interacción con los naturales de quienes obtenían, entre otras cosas, el pescado recién sacado del mar o ríos.

La historia de la medicina señala que descripciones del escorbuto o deficiencia severa de vitamina $C$ se encuentran ya en algunos tratados hipocráticos, así como en las crónicas de las Cruzadas. Fueron los médicos ingleses quienes, debidoal esplendor naval de la corona, pudieron observar y describir científicamente la sintomatología del padecimiento. El primero que lo hizo fue el clínico inglés J. Weyer durante la segunda mitad del XVI. Sin embargo, sería sólo hasta el XVIII cuando el médico naval inglés Lind seffaló la importancia de la dieta para evitar el escorbuto y su curación mediante el consumo del jugo de naranja o limón.

Desde luego que la descripción encontrada en el documento de Juan de Torquemada y que corresponde a la narración de fray Antonio, no puede ser considerada, estrictamente de carácter médico, ya que el fraile carecía de preparación en ese campo. Su interés principal parecería radicar en dar

\footnotetext{
49 Agradecemos a la doctora Ana Cecilia Rodríguez de Romo la información que proporcion 6 relativa al escorbuto.
} 
a conocer un suceso que, según él, afectaba a quienes navegaban por las latitudes que corresponden a la Alta California y que también fue percibido por el general Vizcaino; ambos lo utilizan como argumento para apoyar el poblamiento del puerto de Monterrey. Si bien las intenciones de ambos no corresponde a la de interesados en determinar la sintomatología de un padecimiento particular, su resultado sí contribuye al conocimiento de la insuficiencia vitamínica aguda, $\tan$ frecuente en los largos viajes marítimos de la época. Además, es muy posible que se trate de una de las primeras descripciones del escorbuto incluidas en los diarios o relaciones de las expediciones marítimas en el Mar del Sur.

A manera de final dejaremos claro que las aportaciones al conocimiento científico de los dos viajes de Sebastián Vizcaíno proceden, tanto de la estricta organización que imperó en el segundo de ellos, como de los documentos de fray Antonio de la Ascención y los derroteros y demarcaciones oficiales que confeccionaron el cosmógrafo principal, Gerónimo Martín Palacios y que complementó, con sus dibujos, Enrico Martínez.

La importancia de la participación del fraile carmelita, además de su contribución al conocimiento científico de varios aspectos relacionados con la zona, radica en ser el primer religioso que puso énfasis en la necesidad de poblar la región y de evangelizar a los indígenas acorde con una concepción humanística de esta labor misional. Prueba de ello son sus documentos relacionados con las Californias, ya que fue considerado por las autoridades como uno de los expertos en esa región. Una de ellas, tal vez la más tardía, es la que envía al rey desde su convento en Puebla el 4 de marzo de 1633. En ella, no sólo recomienda la empresa de los capitanes Francisco de Ortega y Juan García de Mercado, quienes en el año de 1632 habían construido a su costa, una fragata pequeña con la que pasaron a las Californias y siguiendo las indicaciones del carmelita pudieron rescatar buena cantidad de perlas, el contenido formal de la carta, radica en la recomendación de poblar la región. Al respecto escribe el carmelita:

las calidades que en si tiene el Reyno de Las Californias, cuan grandes y extendido es y cuan poblado está de indios dóciles y mansos y las muchas riquezas que en sí encierra de perlas, ámbar, plata y otros minerales y los grandes intereses que de pacificarlo a vuestra Mag. se le pueden seguir y las facilidades que en ello hay, el limitado gasto que se puede hacer... más adelante, al concluir su misiva, reitera ...pues soy vasallo y deseo en extremo ver todo aquel Reyno por ser de vta. Mag. y que goce las riquezas de él y que todos los naturales reciban nuestra Santa Fe y vayan a gozar del cielo para que fueron criados. ${ }^{50}$

SO AGI., PATRONATO, 30, R.3. 
Sin duda alguna que con ello se convierte en uno de los precursores en la inicial conformación de la identidad regional. Entre sus aportaciones en este sentido destaca su identificación de la zona del puerto del río del Tizón, actual del valle de Mexicali, con lo que se identifica a este personaje con el proceso de poblamiento de una parte de nuestra actual zona fronteriza del noroeste del país.

\section{BIBLIOGRAFIA}

CEBREIRO BLANCO, Luis. 1943. Colección de diarios y relaciones para la historia de los viajes y descubrimientos, Instituto Histórico de Marina, Madrid.

Colección de Documentos Inéditos relativos al Descubrimiento, Conquista y Colonización de las antiguas posesiones españolas en América y Oceanía. 1864-84, editada por Pacheco, Cárdenas y de Mendoza, Madrid, 42 vols.

DEL PORTILLO, Álvaro. 1982. Descubrimientos y exploraciones en las costas de California, 1532-1650, ediciones RIALP, S.A., Madrid.

FERNÁNDEZ DE NAVARRETE, Martín. 1989. Relación del viaje hecho por las goletas Sútil y Mejicana en el año de 1792, edit. José Porrúa, Madrid.

LEÓN-PORTILLA, Miguel. 1989. Cartografía y crónicas de la Antigua California, UNAM y Fundación de Investigaciones Sociales, A.C., México.

MATHES W., Michael. 1973. Sebastian Vizcaino y la expansion hispánica en el oceáno Pacifico, México.

TORQUEMADA DE, Juan. 1975-85. Monarquía indiana, 3a. edición, 7vols., preparada por el "Seminario para el Estudio de Fuentes de la Tradición Indígena" bajo la coordinación de Miguel León-Portilla, UNAM, México.

VENEGAS, Miguel. 1943. Noticia de la California, México, Luis Álvarez y Álvarez de la Cadena.

WAGNER, Henry R. 1929. Spanish Voyages, San Francisco. 